\title{
Academic Libraries and Affirmative Action: Approaching Cultural Diversity in the 1990s
}

\section{Cliff Glaviano and R. Errol Lam}

Affirmative action in academic libraries has had limited success in improving the percentage of minorities in librarianship. Alternative strategies to correct the unequal representation of minorities in academic libraries are suggested. The authors suggest that more emphasis on the value of establishing an environment of greater cultural diversity within the academic library as well as increasing the cross-cultural sensitivity of academic library staff may have a profound effect on the profession's ability to attract and retain minority librarians to serve the information needs of the multicultural college campus.

Finge ffirmative action to correct previous racial imbalances in staffing throughout institutions of higher education began around 1972. Interest in affirmative action in academic libraries was high initially, but support throughout the profession has fluctuated considerably since 1972. And commitment-in terms of material support for the recruiting and hiring of minority librarians-can be typified as sporadic, usually underfunded, and of short duration.

Prior to affirmative action legislation, black librarians, for example, comprised 6 percent of professional librarians in 1960. By 1974, the percentage of black librarians rose to around 8 percent, though an ALA Black Caucus survey of twelve leading academic libraries (reported by E. J. Josey in 1975 ) indicated that blacks comprised only 2.2 percent of all professionals in those institutions, with very few blacks represented in middle management positions. ${ }^{1,2}$ The ALA Yearbook for 1976 concluded that minority professionals were not being added to librarianship at a significant pace. ${ }^{3}$ Increases in the numbers of black librarians by 1977 could be most optimistically described as "slow but steady." Similarly, statistics in the ALA Yearbooks for 1978, 1981, and 1982 documented deliberate progress in adding minorities to the profession. The first ten years of operating under Equal Opportunity/Affirmative Action legislation had little effect in improving the success of recruiting minorities to librarianship or in raising the percentages of blacks and Hispanics in academic libraries.

The Supreme Court's 1978 decision in the Bakke case (Regents of the University of California vs. Allan Bakke), which recognized race as but one factor in affirmative action decision making, allowed employers to limit minority recruitment to providing only equal employment opportunity. In effect, employers, including academic libraries, began to base recruiting expectations on the pool of minorities available 
within an occupational specialty rather than attempting to recruit and train people of color in order to increase minority representation in the employment pool. Essentially, it became sufficient merely to document that job advertisements were made available to people of color through the general and ethnic media, that potential minority candidates could be identified in a pool of applicants, and, if available in the pool, that minority candidates were interviewed for positions. Equal Employment Opportunity became the de facto standard for minority employment following the Bakke decision while affirmative action programs languished.

Commenting in 1980 on the ability of libraries to implement affirmative action, the ALA Office of Library Personnel Resources (OLPR) reported that, "little progress [was] made in the last three years and ... . [there was] little hope for libraries coping with the problem of a limited minority labor pool in implementing Affirmative Action programs. ${ }^{\prime \prime}$ In 1981, Elizabeth $\mathrm{M}$. Dickinson posed the question, "Is library affirmative action dead?'" ${ }^{\prime 5}$ Her call for library administrators to continue developing and updating affirmative action programs despite slackening efforts by the federal government reflected the profession's conscience, but had little solid influence on contemporary library employment practices. ${ }^{6}$ The scant offerings in the library literature from 1982 to 1986 on affirmative action or minority recruiting and retention would indicate that these topics were not a high priority in the profession. Statistics from 1986 indicating that blacks were only 4.1 percent of academic librarians tend to confirm that most affirmative action programs in place at that time were proving unsuccessful. Further, despite the profession's intellectual commitment to affirmative action, efforts in recruiting and retaining blacks in librarianship were clearly ineffective. The 1986 statistics did show some progress toward better representation of people of color in library management (department head, assistant or associate director, director) than earlier surveys. ${ }^{7}$

Research into the profession's ability to attract and retain people of color con- ducted by Lorene B. Brown, and as part of Equity at Issue, the report of the ALA President's Committee on Library Services to Minorities, indicated crisis-level lack of success through $1986 .{ }^{8,9}$ In 1987 , Josey and Marva L. DeLoach agreed with Brown's conclusions of crisis and called for stronger minority input and representation on policy-making bodies working toward improving library services to minorities, eventually attracting more people of color to the library profession. ${ }^{10}$

The first ten years of operating under Equal Opportunity/Affirmative Action legislation had little effect in improving the success of recruiting minorities to librarianship.

The state of library affirmative action by the end of the 1980s can best be determined from statistics compiled by William E. Moen and Kathleen M. Heim on graduate library school students of 1988 . Their survey of over 3,000 library school students indicated minority representation to be 6.2 percent overall, or, 3.7 percent blacks, 1.1 percent Asians/Pacific Islanders, 0.8 percent Hispanics, 0.6 percent American Indians/Alaskan Natives. The compilers thought that ALA's "Each One Reach One" recruitment initiative from the Office for Library Personnel Resources (OLPR) had served to slow a recent decline in minorities entering the profession. ${ }^{11}$ But, the low percentage of people of color currently in librarianship would also indicate that "Each One Reach One" would result in only miniscule increases in the minority component of the profession in the near future.

\section{MINORITY POOL}

The ALA Yearbooks for 1982 to 1986 seem to indicate by their scant coverage of the particular concerns of black and Hispanic librarians, covered at much greater length in volumes from the 1970 s to 1981 , that the profession's concerns had shifted from the area of hiring and retaining people of 
color. Other social priorities, the status of women in librarianship or the related issue of pay equity, topics of greater immediate concern to the majority of library professionals, received more coverage. Speculation aside, it is safe to say that the percentages of people of color in the candidate pools for professional positions in academic libraries has decreased since OLPR's 1981 report on library staffing ${ }^{12}$ later updated in its 1986 study, Academic and Public Librarians: Data by Race, Ethnicity and Sex. The latter reported that ". . . minorities are recruited into librarianship in a percentage that is less than their availability in the pool of college graduates," and that, "In particular, blacks . . . fall short of their availability in the pool of undergraduate degree holders." 13 The 1986 report indicates concern that declining minority enrollment in library schools, exacerbated by status and image problems of librarians and continued low salaries in entry-level positions, contributes to an increasingly negative assessment of the potential for recruiting people of color to the profession.

Although demographics indicate that the black and Hispanic components of our population comprise nearly 20 percent of all Americans, academic libraries have been content to base their minority recruiting/retention goals at about 5 percent, based on the pool of minority candidates available in the profession according to the most recent (i.e., 1986) statistics from OLPR. ${ }^{14}$ Considering that black librarians may continue to prefer working in public libraries or in traditionally black colleges, even an expectation for a pool of 5 percent may be overly optimistic for academic libraries at predominantly white institutions (henceforth PWIs). In fact, it seems likely that the pool of minority librarians has declined from a 5 percent availability of blacks and Hispanics to even less as those professionals retire or seek other careers. It is apparent that a large increase in the pool of minority librarians will not be forthcoming based on projections of the profession's recruiting potential from the 1986 OLPR study mentioned earlier, and that not all of that minority pool will be available to academic li- braries at PWIs. If one measure of success in recruiting minorities is taken to be enrollment in accredited library schools, a spring 1988 census indicating 3.7 percent blacks and 0.8 percent Hispanics is not encouraging. ${ }^{15}$

The scant offerings in the library literature from 1982-86 would indicate that minority recruiting and retention were not a high priority in the profession.

\section{PAST PRIORITIES}

It should be apparent that although librarianship may remain philosophically committed to increasing minority representation in the profession, the profession has given higher priority to other concerns over the past decade than to recruiting, nurturing, and retaining minority librarians. Academic librarianship, already at a disadvantage in recruiting blacks to PWIs, fails to appeal to targeted minorities as a desirable career. Further, librarianship has not pressured the library schools to compete aggressively with other professional schools. The lack of advertised opportunities for work study or grant/scholarship support for study in librarianship and information science advertised in the Graduate Study Opportunity Pages (GSOP) of the 1989 issues of The Black Collegian witnesses to this failure. Ultimately, academic librarianship appears to have fallen behind higher education in general in its efforts to recruit people of color.

Conversely, higher education's lack of success with affirmative action may be evidence that recruiting to academic librarianship is but a small part of a larger societal problem. Indeed, according to Reginald Wilson, higher education fares quite poorly in recruiting people of color when it ". . . would at first glance, seem to be a propitious time for institutions to move toward racial and ethnic parity. The demographics are all favorable. Minorities of collegegoing age are increasing while the white eighteen-to-twenty-four-year-old popula- 
tion is declining. The post-WWII 'babyboom' generation is aging, and it is estimated that, of those in the professoriate, over 50 percent will be replaced by the end of the century. Despite these facts, the opposite is happening, the presence of minorities in higher education is still declining. "16

\section{THE VALUE OF DIVERSITY}

Beginning in the 1980s, however, the diversity of cultures in our population has been increasingly seen to be valuable in its own right. Business especially has been quick to recognize the implications of a United States population projected by demographers to be composed in the twenty-first century of 30 percent people of color. Further, business has recognized the positive effects of a diversified workforce in a pluralistic working environment, and individual corporations are beginning to express preferences for multiethnic workforces whose compositions mirror the demographics of the country or their local environment. ${ }^{17}$ In short, business has begun to realize increased productivity in terms of product quality, and the quality of work life within the multicultural business, which exceeds that of the monochrome corporation.

Similarly, social work professionals have seen the need to address problems with cross-cultural sensitivity in contacts with clients from the increasingly multicultural society. For example, John S. Wodarski has offered strategies for alleviating racism and encouraging cross-cultural sensitivity in social casework, while $\mathrm{Al}$ Swanson and John A. Brown found that racism originating with supervisors in agencies was a key element in the continuance of negative practices by caseworkers. ${ }^{18,19}$ They found that eliminating racism at the supervisory level could provide strong encouragement for positive changes in casework involving minority clients. In addition to serving as consultants to business, sociologists and social workers who find themselves working in the business community have served in training and personnel development positions. For example, Irene Sidney Cohen described the effectiveness of social work- ers setting up equal opportunity/affirmative action programs. ${ }^{20}$

Human resource managers and training professionals have suggested methods of supervising people of color more effectively while enhancing equal opportunity compliance. John Hodge thinks that, "making a serious effort to help all employees recognize and change discriminating behavior will be the challenge for business for years to come. And training and development professionals will play a large role in making equal opportunity a reality. ${ }^{\prime 21}$ This human relations approach to enhancing majority-minority understanding in the workplace is well documented in the personnel management and training literature. Both theoretical and practical methods for recruiting, acclimating, and training the multiethnic workforce can be found in the writings of Paul G. Engel, Ken Macher, Charles W. Washington, Anthony J. Buonocore, and Dallas R. Crable. ${ }^{22}$

Recently, business has validated its interest in the multicultural society by working to improve affirmative action programs which, in turn, enable corporations to realize the perceived benefits of the multiethnic corporation. American business realizes that it is in its own best interest to establish the multiethnic workforce to gain the advantages that the synergy of cultures adds to corporate competitiveness in both the domestic and the international market for goods and services. To realize the potential of the multiethnic corporation, business has again allocated significant resources to developing true affirmative action programs. Affirmative action strategies now often include instruction in cross-cultural communication and cross-cultural sensitivity training for all employees, and minorities are given instruction in corporate values and behavioral norms of the organization to which they have been recruited. Business' commitment of resources has spurred interest in the development of such training aids as Valuing Diversity, a three-part video program that deals with managing cultural differences, handling diversity at work, and communicating across cultures. This video is an excellent introduc- 
tion to the appreciation of diversity in the workplace as well as a good introduction to the methodologies of personnel management. ${ }^{23}$

\section{STATE OF AFFAIRS IN THE ACADEMIC COMMUNITY}

Obstacles to affirmative action and equal opportunity in academe are not limited to small minority recruitment pools and unequal employment and promotion practices but include recurrent racism and incidences of racial tension. College campuses have experienced continuous turmoil and racial discontent exemplified in reported incidents from virtually all areas of the country. For example, the president of the University of Delaware resigned in October 1988 amidst controversy over alleged racist comments he made about blacks. The comments brought into serious question his commitment to affirmative action. ${ }^{24}$ Since the $1986-87$ academic year, the National Institute Against Prejudice \& Violence has documented reported incidences of racial tension at 175 colleges in its newspaper clippings file. The racial climate on various campuses is best described by minorities as alienation or isolation. ${ }^{25}$ Most whites, on the other hand, are ambivalent toward racial issues. Commenting on one survey of midwestern college freshmen, a director of student affairs found that "students don't agree with negative stereotypes of minorities, but they don't disagree. They are bothered by racial tension, but they want it to go away. They don't feel they've done anything for which they need to make up. ${ }^{\prime 26}$

Librarianship, as reported in recent library literature, like the academic community, is not immune to the ills of society. Elizabeth Martinez Smith wrote on the pervasive, omnipresent atmosphere of racism encountered in the profession, and Patrick A. Hall, in an article on his experience as a black reference librarian at a PWI, describes much the same reception. ${ }^{27,28}$

\section{WHAT CAN ACADEMIC LIBRARIES DO?}

Though it is not the primary function of academic libraries to define the mul- tiethnic society or the methodologies the university might employ to educate for the pluralistic society, the libraries can be very influential in establishing and demonstrating a pluralistic environment from which the information needs of all campus cultures might be serviced. Academic libraries in the PWIs must take the initiative in creating a local multicultural environment through displays, collections, staff,

\section{If one measure of success in recruit- ing minorities is taken to be enroll- ment in library schools, a spring 1988 census is not encouraging.}

and services. That is, academic libraries should provide an environment that proclaims an appreciation of the contributions of minority cultures in American society, thus stimulating and nurturing cross-cultural appreciation. Creating this necessary environment-an atmosphere that will enhance the image of the academic libraries and academic librarianship for majority and minority patrons-will be very challenging in these times of tight budgets and scarce resources.

Realizing this, librarians must give consideration to tactics that have been attempted and that have met with fair success in other issues of importance to librarianship: volunteer work, networking, lobbying, and activism. Successful techniques from other problems can influence the course of affirmative action at the local level. This suggests nothing less than a grassroots, individual effort to initiate programming, networking, and personal recruitment to the cause of affirmative action in each academic library. To effect eventual demographic parity between the academic library staff and the population of the surrounding area of the parent institution, academic librarians must begin to exert influence within libraries and parent institutions by taking a proactive stance, influencing the direction of, and effecting change toward affirmative action. It cannot usually be expected that academic libraries in PWIs, themselves parts of PWIs 
and serving the information needs of the PWIs, will hold attitudes much different from their parent institutions. Academic libraries may lack multicultural atmospheres, and their library staff, like the surveyed freshmen, may not feel personally responsible for alleviating racial problems on campus.

Improving the pluralistic nature of the library and its services would certainly strengthen the base from which academic libraries reach out to minorities on campus. Enhancing the library environment and improving the staff's cross-cultural sensitivity may have extraordinary influence on the quality of services offered minority clientele. Library efforts in creating the pluralistic library will undoubtedly be noted by minorities, thus making the library both more desirable as an employer and as an information source. As reports of academic libraries being pluralistic and caring workplaces spread, recruitment and retention of minority staff in clerical, paraprofessional, and professional positions should improve substantially.

\section{TOOLS}

Calling for volunteer work, networking, lobbying or other forms of activism rising from a commitment to affirmative action implies an expectation that academic librarians will become increasingly committed to serving the pluralistic society of the 1990s. It must be realized, however, that changes in practice that move the profession toward real improvement in affirmative action will probably originate with underfunded individuals or small groups in local academic libraries. The following four sections outline inexpensive tools, resources, and methods that might be used to initiate such change.

\section{Networking}

Several cumulative types of resources are of potential value to an academic librarian wishing to implement programs in valuing diversity. Often knowledgeable persons and organizations either on campus or in the local community are interested in improving minority representation on campus or generally improving race relations. By networking with these individuals or groups as well as with other concerned librarians, events can be organized in which local experts may be engaged to assist with or facilitate library programming. Contacts with local personnel and organizations can result in additional ideas for programming. The local network also serves as a support mechanism for the activist librarian. Though local experts in the network will not usually plan library programming, members of the faculty and staff in such areas as ethnic studies, minority affairs, communications, or women's studies can be extremely important in suggesting activities and resources for exploring pluralism in addition to participating in the programs themselves.

At the national level, library organizations such as REFORMA, the ALA Black Caucus, Office of Library Personnel Resources (OLPR), Office for Library Outreach Services (OLOS), ACRL Recruitment of Underrepresented Minorities Task Force, and the Ethnic Materials and Information Exchange Round Table (EMIERT) are sources of current information, often providing programs or suggesting program ideas of interest for enhancing cultural pluralism. Establishing and maintaining contact with such library organizations and individual members of these organizations can expand the network greatly with little additional expense to the academic library or the individual librarian. Library associations within a state may have caucuses, interest groups, or round tables that could be important for network expansion. In addition, nonlibrary organizations at the state and national level, often with chapters on campus or in the community, are deeply committed to ethnic pluralism.

\section{Literature}

Much can be gained from materials already available in academic libraries. Current awareness materials include periodicals such as Equal Opportunity, Black Issues in Higher Education, The Affirmative Action Register, and The Chronicle of Higher Education. The business and sociological literature continues to reflect strong interest in the multicultural workforce and American 
pluralistic society. Also, increasing interest in minority and cultural concerns can be found in the library literature. Examples of programming and resource materials are available in such works as Minorities on Campus: A Handbook for Enhancing Diversity, offering practical advice and examples of successful cultural diversity programs in academe; and Achieving Faculty Diversity: A Sourcebook of Ideas and Success Stories, highlighting programs from colleges and universities that have been successful in hiring black, Latino, Native American, and Asian-American faculty. $^{29,30}$

\section{Academic libraries should provide an environment that proclaims an ap- preciation of the contributions of $\mathrm{mi}$ - nority cultures in American society.}

\section{Conferences}

Conferences throughout the year deal with various aspects of cultural pluralism and/or recruiting and retention of minorities. The (Oklahoma) "National Conference on Racial and Ethnic Relations in American Higher Education," held annually since 1988, is an attempt to bring scholars and campus leaders together to share, discuss, and debate ideas concerning enhancing the role and participation of people of color in higher education. Conferences called at regular intervals to address more focused aspects of pluralism in higher education include, for example, "The National Conference on Black Student Retention in Higher Education, " and the annual conferences of The Association of Black Women in Higher Education. Other conferences such as "From the Eurocentric University to the Multicultural University: The Faculty's Challenge for the 21st Century," (1989) occur one time only to address an important aspect of pluralism.

Conferences offer opportunities for expanding personal networks with conference speakers and attendees in addition to updating knowledge on specific concerns of both pluralism and the recruiting and retention of minorities. The costs of the national conferences vary widely. Teleconferencing and local/state conferences often offer economical alternatives to the more expensive national conferences, and some, like ALA preconferences, may provide economies of convenience.

\section{Local Program Resources}

Local programs, like conferences, vary widely in cost. They range from full workshops with professional facilitators/teachers, to local film series on cultural relations, with or without volunteer facilitators. Resources may be chosen to address particular aspects of cultural pluralism or to be of interest to targeted groups. Many inexpensive videos suitable for inclusion in local programming can be located via the personal network of organizations and individuals suggested earlier. Among videos that are available either at no cost or at low cost within the academic community are Valuing Diversity, mentioned earlier, and Racism 101, a program from the PBS Frontline series that provides a chilling insight into racism on campus through early 1988. ${ }^{31}$ Recommendations from networkers can provide additional titles for materials suitable for local programs, and catalogs of film/video libraries or rental lists are often annotated and indexed by subject. In general, videos and films will provide inexpensive programming resources. They are nonthreatening, readily available, and adaptable to many consciousness-raising scenarios.

Success in local programming that endeavors both to enhance the pluralistic nature of the library environment and to improve the cultural relations skills of library staff is not directly related to the size of the budget allocated to affirmative action. Shortfalls in dollars can be made up in energies and commitment by individual librarians and the networks they have created. Inexpensive programming still can be excellent. Waiting for a bigger budget may not necessarily guarantee academic libraries substantial success at affirmative action or in meeting the needs of a multicultural society. 


\section{COMMITMENT, PROGRESS, PATIENCE}

Librarianship's intellectual commitment to affirmative action may well serve library staff in terms of obtaining release time from normal duties to pursue affirmative action aims. Even with release time, however, the effort and time commitment necessary to remain informed and keep in contact with those individuals and groups with which a librarian might be networking is considerable. It is responsible to assume that burnout is a distinct possibility and that results will not be apparent overnight. Higher education has been particularly slow in effecting affirmative action change. Principles advanced by Howard L. Fromkin and John J. Sherwood in 1974, for example, may still be used to steer administrators toward more racially balanced faculty and staff. ${ }^{32}$ Additionally, prescriptions for eliminating racism advanced by Judy Katz in White Awareness are as valid today as they were in 1978 when the work was first published. ${ }^{33}$ Ten years later, the continuing need to address racism was again underlined in Eliminating Racism: Profiles in Controversy. ${ }^{34}$

Internal programs can significantly influence creation of a pluralistic environment in the library and can serve to augment outreach to minorities in the academic community. Programming initiated by the University of Michigan Libraries in the spring of 1988 continues to develop and provides a convenient model of what can be accomplished. ${ }^{35}$ The program can be described as a vision for enhancing race relations on campus, fueled by volunteers, given impetus and support by a committed library administration, and funded chiefly by release time from scheduled library duties.

\section{UNIVERSITY OF MICHIGAN}

In conjunction with a library-sponsored general meeting, "Overcoming Racism: Exploring the Value of Diversity," called to address the problem of institutional racism at the University of Michigan in 1988, thirteen volunteers from various job categories were trained as workshop facilitators. Following a series of workshops, these facilitators served as discussion leaders for groups continuing to probe topics related to diversity. A continuing group, the Library's Diversity Task Force, chiefly comprised of volunteers from the workshop facilitators or discussion groups continues to meet twice monthly to discuss further programming in the interest of improving diversity within the libraries.

\section{Efforts in creating the pluralistic library will undoubtedly be noted by minorities, thus making the library more desirable as an employer and as an information source.}

The Diversity Task Force has sponsored film series and discussions centered on the experiences of blacks, Hispanics, and other ethnic groups in the United States. A day-long workshop was subsequently held to evaluate the Library's progress toward diversity and the continuing role of the Task Force in promoting pluralism. The Task Force has continued to coordinate diversity activities in the Libraries. Many of the activities coordinated by the Task Force have been efforts in response to suggestions or concerns of library staff expressed in the continuing discussion groups.

Continuous support by Library administration was evidenced throughout diversity programming and planning efforts at Michigan from its accommodation of scheduling conflicts and the generous allowance of release time for Task Force members and for other library staff participating in diversity activities. As a result in part from emphasizing the value of diversity and taking steps to enhance diversity in the workplace, recruitment and retention of minority staff in the University of Michigan Libraries has improved markedly. The percentage of minority professional librarians at Michigan in late 1988 at 21.5 percent was more than double the 9.39 percent reported for general ARL libraries reported by the Association of Re- 
search Libraries in its 1987 Annual Salary Survey. ${ }^{36}$

\section{SUMMARY}

Although the employment potential for minority professionals in librarianship warrants optimism, insufficient opportunities have been provided and inadequate encouragement given so far to people of color, resulting in an inadequate representation in academic libraries. The profession continues to be concerned over the shortage of librarians of color while it becomes ever more aware of the need to adapt library services to an increasingly pluralistic American society in a multidiverse world. ${ }^{37}$

While academic librarianship is intellectually and morally committed to affirmative action, giant steps must be taken to insure that decreases in the numbers of academic librarians of color not continue into the 1990s. Libraries in the PWIs, like their parent institutions, continue to emphasize recruitment in terms of the availability of minorities in the employment pool. However, so far, the PWIs have refrained from defining the role by which they might enhance the creation of a pluralistic society on campus. The PWIs have neither developed pluralism on campus nor provided the methodology for educating a multicultural society. Not surprisingly, racial conflicts and tensions recur in the PWIs.

Past practice in affirmative action, including calls for special minority recruitment to librarianship and providing scholarships and internships for graduate information study, routinely has been inadequate for improving the representation of people of color in academic librarianship. At present, academic librarians may be more acutely aware of shrinking budgets and may be more sensitive to the minority representation in a given employment pool than to the underrepresentation of people of color in academic librarianship. To change academic librarianship to meet the needs of a pluralistic society, attitudes must be transformed, services adapted, the environment altered, and openness and acceptance adopted. The academic library itself must be changed.
The most obvious potential agents for such change are committed academic librarians.

The literature reflects continuing concern with improving the quality of the interface of library services with minority clients and the potential for recruiting from underrepresented groups for library positions. Library literature reflects calls for improving communication between people of color and the white majority whether between colleagues or between client and reference librarian. ${ }^{38}$ The literature also reports explorations of the role of libraries in the future pluralistic society. In 1988 for example, the California Library Association titled its 90th annual meeting, "Libraries: Uniting Cultures Through Knowledge." ${ }^{\prime 39}$ The climate in the profession appears generally to be open to both designing services for a pluralistic American society and to improving minority representation in the profession. And, following some success in improving the status of women and some advancement toward pay equity, librarianship's social conscience may now include increased emphasis on minority recruitment and retention, and valuing diversity in the academic library.

Academic librarians committed to changing both the atmosphere in, and minority perceptions of, information organizations in the PWIs are easily the most important resources available which, through individual effort, networking, and cooperative programming, may enable the profession to meet the challenges of an increasingly pluralistic American society. Once academic librarians succeed in reestablishing affirmative action as a primary goal of the profession, and validate commitment to a diverse society at the local level, the potential for minority recruitment to academic librarianship will be vastly improved. Academic librarianship will then be an attractive career choice for people of color and not, as it appears now, a career of frustration, low status, and limited potential for success. Academic librarianship needs to be vibrant and vital in its pluralism, not low profile. The profession needs to be reaching out to minorities and celebrating cultural diversity, not uncon- 
sciously perpetuating the culturally neutral, equal education opportunity atmosphere that is now pervasive in the PWIs.
Individual librarians can make it happen in the 1990s beginning now.

\section{REFERENCES AND NOTES}

1. Elizabeth M. Dickinson, "Personnel and Employment: Affirmative Action," in ALA Yearbook 1976 (Chicago: American Library Assn., 1976), p.258.

2. E. J. Josey, "Can Library Affirmative Action Succeed?" Library Journal 100:30-31 (Jan. 1975).

3. Dickinson, "Personnel and Employment," p.258.

4. Yolanda J. Cuesta, "Personnel and Employment: Affirmative Action," in ALA Yearbook 1981 (Chicago: American Library Assn., 1981), p.218.

5. Elizabeth M. Dickinson, "Is Affirmative Action Dead?" in ALA Yearbook 1982 (Chicago: American Library Assn., 1982), p.209-10.

6. Carol Learmont, "Personnel and Employment: Recruitment and Selection," in ALA Yearbook 1982 (Chicago: American Library Assn., 1982), p.210.

7. American Library Association, Office of Library Personnel Resources, Academic and Public Librarians: Data by Race, Ethnicity and Sex (Chicago: American Library Assn., 1986), p.7.

8. Lorene B. Brown, "A Crisis in Librarianship: The Decline in the Number of Minorities Entering the Profession Since 1979" (paper delivered at the Black Caucus of the American Library Association Meeting, Chicago, Jan. 19, 1986).

9. American Library Association, President's Committee on Library Services to Minorities, Equity at Issue: Library Service to the Nation's Four Major Minority Groups, 1985-86 (Chicago: American Library Assn., 1986), p.13.

10. E. J. Josey and Marva L. DeLoach, "Library Services to Ethnic Communities," Ethnic Forum 7:17-35 (1987).

11. William E. Moen and Kathleen M. Heim, "The Class of 1988: Librarians for the New Millenium," American Libraries 19:858-60 (Nov. 1988).

12. American Library Association, Office of Library Personnel Resources, The Racial, Ethnic, and Sexual Composition of Library Staff in Academic and Public Libraries (Chicago: American Library Assn., 1981).

13. ALA Office of Library Personnel Resources, Academic and Public Librarians, p.23.

14. U.S. Bureau of the Census, Statistical Abstract of the United States: 1988 (Washington, D.C.: U.S. G. P. O., 1987).

15. Moen and Heim, "The Class of 1988," p.858-60.

16. Reginald Wilson, "Recruitment \& Retention of Minority Faculty and Staff," AAHE Bulletin 39, no.6:12 (Feb. 1987).

17. John P. Fernandez, Racism and Sexism in Corporate Life: Changing Values in American Business (Lexington, Mass.: Lexington Books, 1981).

18. John S. Wodarski, "Strategies for the Alleviation of Institutional Racism in Services Offered by Social Work Agencies," Journal of Social Work 4, no.1:51-61 (Spring 1977).

19. Al Swanson and John A. Brown, "Racism, Supervision, and Organizational Environment," Administration in Social Work 5, no.2:59-68 (Summer 1981).

20. Irene Sidney Cohen, "Devising Ways to Implement Affirmative Action Goals," Practice Digest 3, no.1:26-28 (1980).

21. John Hodge, "Common-Sensical Approach to Supervising Minorities," Supervisory Management 28, no.29:24-27 (Sept. 1983).

22. Paul G. Engel, "Helping Minorities, Corporations Mesh," Industry Week 223, no.4:22-28 (Nov. 12, 1984); Ken Macher, "The Politics of Organizations," Personnel Journal 65, no.2:80-84 (Feb. 1986); Charles W. Washington, "Acculturation of Minorities in Large Organizations," The Bureaucrat 16:29-34 (Spring 1987); Anthony J. Buonocore and Dallas R. Crable, "Equal Opportunity: An Incomplete Evolution," Personnel Journal 65, no.8:32-35 (Aug. 1986), are among many recent articles discussing aspects of minority recruitment and orientation.

23. Valuing Diversity (San Francisco: Copeland Griggs Productions, 1988) 3 videotapes, $30 \mathrm{~min}$. ea.

24. "Embattled President at U. of Delaware Quits After 16 Months on the Job," The Chronicle of Higher Education 35, no.10:A11, A14 (Nov. 2, 1988).

25. Denise K. Magner, "Blacks and Whites on the Campuses: Behind Ugly Racist Incidents, Student Isolation and Insensitivity," The Chronicle of Higher Education 35, no.33:A28 (April 26, 1989).

26. Ibid., p.A29. 
27. Elizabeth Martinez Smith, "Racism: It Is Always There," Library Journal 113, no.18:35-39 (Nov. 1, 1988).

28. Patrick A. Hall, "Yassuh! I's the Reference Librarian!" American Libraries 19:900-01 (Nov. 1988).

29. Madeleine F. Green, ed., Minorities on Campus: A Handbook for Enhancing Diversity (Washington: American Council on Education, 1989).

30. Jeri Spann, Achieving Faculty Diversity: A Sourcebook of Ideas and Success Stories (Madison, Wis.: Office of Equal Opportunity Programs and Policy Studies, University of Wisconsin System, 1988).

31. Racism 101 is but one example of programs from public and commercial television that may be used as videos for local programming and quite often relevant videos are already available on campus, having been obtained as curriculum support materials.

32. Howard L. Fromkin and John J. Sherwood, eds., Integrating the Organization (New York: Free Press, 1974).

33. Judy H. Katz, White Awareness: Handbook for Anti-Racism Training (Norman, Okla.: University of Oklahoma Press, 1978).

34. Phyllis A. Katz and Dalmas A. Taylor, eds., Eliminating Racism: Profiles in Controversy (New York: Plenum Press, 1988).

35. Robert M. Warner, Point of Intersection: The University Library and the Pluralistic Campus Community (Ann Arbor, Mich.: University of Michigan Library, 1988).

36. Ibid., p.4.

37. L. C. Jolivet, "Preparation of Librarians to Serve a Multicultural World," WLW Journal 12:3-6 (Summer 1988).

38. R. Errol Lam, "The Reference Interview: Some Intercultural Considerations," $R Q$ 27:390-95 (Spring 1988).

39. Michael Gorman, "Exhilarating Diversity, Uncertain Finances," American Libraries 20:81-85 (Jan. 1989).

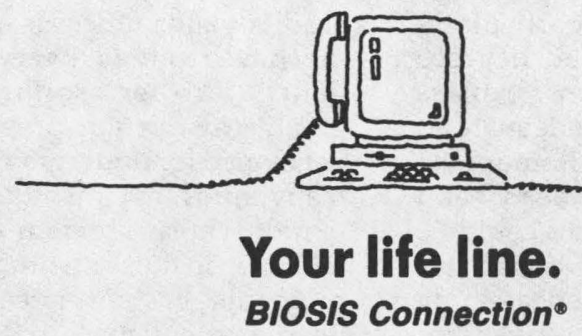

Keeping your finger on the pulse of biological and biomedical research information is as easy as pressing a button. The BIOSIS Connection is your low-cost direct line to the world's largest abstracting and indexing service for the life sciences, and you can be part of it!

patents, books, meetings, theses, upcoming events and employment openings.

All it takes to extend your life line is a modem-equipped personal computer or terminal and a phone line. And what's more, you need no special search skills to use the BIOSIS Connection!

This exciting and invaluable computerized information service connects you to all the research and professional information you need, with current awareness databases covering journal literature,

Put your fingers on the life line. . Subscribe now to the BIOSis Connoction!

Busers Connection is a registered trademark of Blosis.

For more information, a Sign-Up Kit, or a free demonstration disk, contact BIOSIS, 2100 Arch Street, Dept. CRL1190LL, Philadelphia, PA 19103-1399 USA. Telephone (215) 587-4800 worldwide; toll free 1-800-523-4806 (USA except PA); Telex 831739; Fax (215) 587-2016. 